\title{
CARACTERIZAÇÃO MORFOANATÔMICA DO MELÃO GÁLIA NO PONTO DE COLHEITA ${ }^{1}$
}

\author{
RAILENE HÉRICA CARLOS ROCHA², EBENÉZER DE OLIVEIRA SILVA², \\ LUIZ CARLOS CHAMHUM SALOMÃO ${ }^{4}$, MARÍLIA CONTIN VENTRELLA ${ }^{5}$
}

RESUMO - O objetivo deste trabalho foi caracterizar morfoanatomicamente o melão 'Gália', com ênfase no exocarpo e mesocarpo, no ponto de colheita. Os frutos foram obtidos em propriedade comercial localizada no município de Mossoró-RN, aos 65 dias de cultivo após a semeadura. Em laboratório, realizou-se a caracterização morfológica através da determinação da massa, espessura da polpa, comprimento longitudinal e transversal, relação de formato e índice de rendilhamento. Análises em tomografia de ressonância magnética nuclear foram realizadas para a determinação da integridade dos tecidos. As análises anatômicas foram realizadas utilizando-se de microscopia de luz e eletrônica de varredura. O melão Gália, híbrido 'Solar King', foi caracterizado como fruto do tipo baga, de formato esférico, com massa média de $1.021 \mathrm{~g}$. As imagens sugerem que, na região do mesocarpo, o metabolismo acentuado e o amadurecimento mais avançado nos tecidos do centro do fruto podem ser responsáveis pelo descolamento da placenta e o amaciamento mais rápido dos tecidos em volta da cavidade interna. As áreas rendilhadas, juntamente com as ceras epicuticulares e a estrutura adensada das primeiras camadas subepidérmicas podem contribuir para o controle da perda de umidade do fruto e a resistência às injúrias mecânicas.

Termos para indexação: Cucumis melo L., morfologia, colheita.

\section{MORPHOANATOMICAL CHARACTERIZATION OF GÁLIA MELON IN THE HARVEST POINT}

\begin{abstract}
The objective of this work was to characterize the morphoanatomical structure of Galia melon, with emphasis in the exocarp and mesocarp, in the harvest point. Melons were purchased from a commercial farm in the Municipality of Mossoró, RN, 65 days of cultivation after sowing. It was carried out in the laboratory, the morphological characterization through the determination of the mass, pulp thickness, longitudinal and cross length, shape relation and reticulation index. Analyses in nuclear magnetic resonance tomography were realized for the determination of the integrity of tissues. The anatomical analyses were realized using light and electron scanning microscopes. The Gália melon, hybrid 'Solar King', was characterized like a fruit of berry type, of spherical format, with middle mass of $1021 \mathrm{~g}$. The images suggest that in the region of the mesocarp, the accentuated metabolism and the advanced maturing in the tissues from the center of the fruit can be responsible for the displacement of the placenta and the soften of the tissues around the internal cavity. The reticulation, together with epicuticular waxes and denser structure of the first parenchymatic layers can contribute to the control of moisture loss of the fruit and the resistance to the mechanicals injuries.
\end{abstract}

Index terms: Cucumis melo L., morphology, harvest.

\footnotetext{
'(Trabalho 095-09). Recebido em: 15-04-2009. Aceito para publicação em: 27-11-2009.

${ }^{2}$ Eng. Agr ${ }^{a}$, Prof ${ }^{\text {a }}$ D.Sc, UFCG. Centro de Ciência e Tecnologia Agroalimentar, Campus de Pombal-PB. CEP: 58.840, e-mail: raileneherica@ccta.ufcg.edu.br

${ }^{3}$ Eng.Agro. Pesquisador. DSc. EMBRAPA - Agroindústria Tropical, Fortaleza-CE, e-mail: ebenezer@cnpat.embrapa.br

${ }^{4}$ Eng. Agro Prof. D.Sc, UFV. Departamento de Fitotecnia. CEP: 36570-000, Viçosa-MG. e-mail: 1salomao@ ufv.br

${ }^{5}$ Bióloga. Profa. D.Sc., UFV. Departamento de Biologia. CEP: 36570-000, Viçosa-MG. e-mail: ventrella@ufv.br
} 


\section{INTRODUÇÃO}

O meloeiro (Cucumis melo L.) é originário do sudoeste da África e Índia peninsular. Sua maior diversidade botânica é encontrada na Índia, Irã, Afeganistão e China (BISOGNIN, 2002). É uma espécie comercialmente importante no mundo inteiro, sendo os frutos consumidos in natura, como ingrediente de saladas e na forma de suco.

No Brasil, a espécie é conhecida desde o século XVI, quando foi trazida, provavelmente, pelos escravos. No Nordeste, o meloeiro chegou por volta dos anos 60 do século passado. Atualmente, esta é a principal região produtora, com destaque para os Agropolos de Mossoró e Açu, no Rio Grande do Norte, e do Baixo Jaguaribe, no Ceará, cujos melões mais cultivados pertencem aos tipos Amarelos (lisos ou rugosos), Gália, Cantalupe, Charentais (lisos e rendilhados) e Verde Espanhol (TORRES, 1997).

O meloeiro tipo Gália é uma planta anual, herbácea, andromonoica e ocasionalmente monoica, possui um sistema radicular superficial e praticamente sem raízes adventícias, com baixa capacidade de regeneração quando danificado, com caule de crescimento rasteiro ou prostrado, provido de nós com gemas, que se desenvolvem em gavinhas, folhas, novos caules ou ramificações (LORENZI, 2006). Os frutos, conhecidos como melões nobres, são aromáticos, de casca rendilhada e apreciados pelo elevado conteúdo de sólidos solúveis, entre 9 e 11 ${ }^{\circ}$ Brix (MENEZES, 1996).

Os tecidos de revestimento e de preenchimento do fruto assumem papel fundamental para a determinação da qualidade no ponto de colheita, e constituem o exocarpo e o mesocarpo, respectivamente. Os tecidos de revestimento determinam o aspecto externo, rendilhamento, coloração, brilho (GALAZ, 2006) e limitam o ambiente interno do ambiente externo do produto, sendo importantes após a colheita. Os tecidos de revestimento influenciam diretamente na troca de gases, como vapor de água, oxigênio e dióxido de carbono, na resistência ao ataque de insetos e patógenos, na resistência às injúrias pelo frio e mecânicas, durante o manuseio (KAYS, 1991). Os tecidos de preenchimento, localizados mais internamente, armazenam grande volume de água, minerais e carboidratos, importantes para a dieta alimentar (KAYS, 1991; COMBRINK et al., 2001). São responsáveis pela determinação do volume do fruto e manutenção de características importantes para o mercado, como textura, teor de sólidos solúveis e aroma.

O objetivo deste trabalho foi caracterizar morfoa- natomicamente o melão Gália, no ponto de colheita comercial. Embora haja estudos relacionados à estrutura anatômica do meloeiro, a caracterização morfoanatômica do melão Gália, no ponto de colheita comercial, é desconhecida, podendo servir de complemento aos trabalhos existente sobre caracterização física e química do melão (MENEZES, 1996; COMBRINK et al., 2001; MORAIS et al., 2004) e como suporte para a compreensão do comportamento dos tecidos submetidos a injúrias mecânicas e ao armazenamento.

\section{MATERIAL E MÉTODOS}

Melões Gália, híbrido 'Solar King', foram obtidos em uma propriedade comercial localizada no município de Mossoró-RN, aos 65 dias de cultivo após a semeadura. Mossoró está situada a aproximadamente $18 \mathrm{~m}$ de altitude, com coordenadas geográficas $5^{\circ} 11^{\prime}$ de latitude sul e $37^{\circ} 20^{\prime}$ de longitude oeste do meridiano de Greenwich. Segundo a classificação de Köeppen, o clima desta região é do tipo BSwh', caracterizado como quente e seco.

A área de plantio foi de aproximadamente 2 ha, com espaçamento de $2 \mathrm{~m}$ entre linhas e 0,5 $m$ entre plantas, equipada com sistema de irrigação por gotejamento em linha, com irrigações feitas diariamente. Condução, adubação, irrigação e demais tratos culturais foram realizadas utilizando as normas de PIFmelão (FREITAS, 2003).

A colheita foi realizada cuidadosamente pela manhã, conforme os critérios adotados pela empresa agrícola, estabelecendo-se o ponto de colheita com base em amostragens de frutos na linha de plantio para a verificação do teor de sólidos solúveis ao redor de $10 \%$ (FREITAS, 2003), determinado com o auxílio de refratômetro de campo. Após a colheita, os melões foram colocados em caixas de papelão ondulado com capacidade para cinco frutos e transportados em carro com ar condicionado para o Laboratório de Fisiologia e Tecnologia Pós-Colheita da Embrapa Agroindústria Tropical em Fortaleza-CE.

\section{Análises Morfológicas}

A caracterização morfológica do melão foi realizada por meio da determinação da massa, espessura de polpa, comprimento longitudinal e diâmetro, relação de formato e índice de rendilhamento, utilizando-se de quatro frutos.

A massa dos frutos foi determinada em balança semianalítica e expressa em grama (g). Para as medidas de espessura de polpa, comprimento e diâmetro, utilizou-se de paquímetro digital Ultra-Cal Mark III, marca Fowler Sylvac, sendo expressas em 
centímetros $(\mathrm{cm})$. Para as medições, os frutos foram cortados no sentido longitudinal, utilizando-se das duas metades do fruto partido. Para determinar a espessura de polpa, realizaram-se quatro leituras, sendo duas leituras por metade do fruto partido. Para a avaliação de comprimento, considerou-se a medida entre o ápice e a base do fruto e, para o diâmetro, considerou-se a maior medida perpendicular ao sentido longitudinal. Posteriormente, calculou-se a média de cada medida por fruto.

A relação de formato e o índice de rendilhamento foram determinados de acordo com a metodologia proposta por Morais et al. (2004). A relação de formato (RF) foi obtida pela relação entre o comprimento e o diâmetro do fruto, classificando-o em: comprimido $(\mathrm{RF}<0,9)$; esférico $(0,9 \leq \mathrm{RF} \leq 1,1)$; oblongo $(1,1<R F \leq 1,7)$, e cilíndrico $(R F>1,7)$. $\mathrm{O}$ índice de rendilhamento foi estabelecido por meio de escala de notas, de acordo com a intensidade de rendilhamento, onde: 1 - totalmente liso ( $\geq 90 \%$ liso); 2 - levemente rendilhado ( $>50 \%$ e $<90 \%$ liso); 3 - rendilhamento mediano $(50 \%$ liso e $50 \%$ rendilhado); 4 - rendilhado ( $>50 \%$ e $<90 \%$ rendilhado), e 5 - totalmente rendilhado ( $\geq 90 \%$ rendilhado).

\section{Nuclear}

Tomografia de Ressonância Magnética

A análise por tomografia de ressonância magnética nuclear foi realizada para a caracterização dos tecidos internos do melão. Uma amostra contendo quatro frutos foi analisada aproximadamente $48 \mathrm{~h}$ após a colheita. As imagens foram registradas em tomógrafo de ressonância magnética nuclear Varian Inova, com densidade de fluxo magnético de 2 Teslas, após sua inserção em bobina de radiofrequência do tipo "gaiola", com diâmetro interno de $14 \mathrm{~cm}$, operando na frequência de 85,53 MHz. Para a obtenção das imagens, ondas de radiofrequência interagiram com momentos magnéticos de prótons de hidrogênio $\left({ }^{1} \mathrm{H}\right)$, que são essencialmente das moléculas de água que compõem os frutos. Para cada fruto, obtiveramse tomogramas simétricos a partir do centro do fruto. As imagens foram geradas em matrizes de 256 x 256 pixels, em fatias de $2 \mathrm{~mm}$ de espessura, espaçadas a $1 \mathrm{~cm}$, em torno do centro do fruto. As imagens bidimensionais foram analisadas com relação à forma, localização e textura dos graus de cinza, que indicam as situações da água, mais móvel (livre) ou mais ligada aos tecidos sadios.

\section{Microscopia de Luz}

Para a análise dos tecidos por microscopia de luz, utilizaram-se dois frutos, de onde se retiraram três amostras da região equatorial de cada fruto, sendo uma amostra contendo exocarpo e parte do mesocarpo, outra contendo apenas o exocarpo, e outra, apenas o mesocarpo. As amostras foram fixadas em solução de Karnovski (1965), desidratadas em série etílica e incluídas em metacrilato (Historesin, Leica).

Do material incluído, foram obtidas secções com $5 \mu \mathrm{m}$ de espessura em micrótomo rotatório Leica 2065, utilizando-se de navalha de tungstênio. As amostras contendo exocarpo e parte do mesocarpo, e as amostras contendo apenas o mesocarpo foram seccionadas no sentido transversal, e as amostras contendo apenas o exocarpo foram seccionadas no sentido paradérmico.

As lâminas foram coradas com azul de toluidina a $0,12 \%$, em bórax $5 \%$, por 60 segundos, e fucsina básica a $0,05 \%$, por 8 segundos (KRAUS; ARDUIN, 1997). As lâminas permanentes foram montadas em resina sintética (Entellan). As imagens foram obtidas em fotomicroscópio Olympus AX70 equipado com sistema U-Photo e câmera digital (Diagnostic Instruments Work, modelo Spot Insight) e acoplado a um microcomputador equipado com software de captura de imagens (Spot Basic).

\section{Microscopia Eletrônica de Varredura}

A análise dos tecidos por microscopia eletrônica de varredura foi realizada conforme a metodologia descrita por Kitajima (1997). Utilizaram-se dois frutos por tratamento, onde se retiraram três amostras da região equatorial de cada fruto, sendo uma amostra contendo exocarpo e parte do mesocarpo, outra contendo apenas o exocarpo, e outra, apenas o mesocarpo. As amostras foram fixadas em solução de Karnovski (1965), tampão cacodilato de sódio $(0,05 \mathrm{M} ; \mathrm{pH} 7,2)$ e tetróxido de ósmio a $1 \%$, por 1 hora cada, na temperatura ambiente $\left(25^{\circ} \mathrm{C}\right)$. Em seguida, foram desidratadas em série crescente de acetona, secas até o ponto crítico no aparelho de secagem Emitech K850, metalizadas com ouro em aparelho Emitech K550, e examinadas ao microscópio eletrônico de varredura Zeiss DSM 940 A, com voltagem de aceleração de $10 \mathrm{kV}$. As imagens foram obtidas com o auxílio de uma câmara fotográfica digital Sony, modelo Cyber-Shot DSC-P93A.

\section{RESULTADOS E DISCUSSÃO}

\section{Aspectos Morfológicos do Fruto}

O melão Gália, híbrido 'Solar King', assim como os demais melões foram classificados como baga do tipo melonídio, que é um fruto simples, carnoso, tricarpelar, unilocular, plurispérmico e com placentação parietal (SOUZA, 2006), constituído por 
três camadas distintas, o exocarpo, o mesocarpo e o endocarpo. O exocarpo, região mais externa e não comestível, foi caracterizado pelas malhas que formaram um emaranhado de redes ou rendilhamentos, característicos desta variedade. $\mathrm{O}$ mesocarpo, parte de maior interesse, por ser a região comestível, é carnoso e rico em carboidratos, principalmente sacarose (VILLANUEVA et al., 2004). O endocarpo foi caracterizado como a região mais interna em volta das numerosas sementes que se encontraram dispersas na cavidade interna do fruto.

No ponto de colheita, os frutos tiveram, em média, 1.021,97g de massa, 3,91 cm de espessura de polpa, $12,91 \mathrm{~cm}$ de comprimento e $11,96 \mathrm{~cm}$ de diâmetro, sendo classificados como esféricos, com 1,08 de relação de formato, rendilhado com nota 4 de índice de rendilhamento ( $>50 \%$ e $<90 \%$ rendilhado), coloração da casca predominantemente amarela e polpa branco-esverdeada (Tabela 1).

Morais et al. (2004) também não observaram diferenças significativas quanto ao comprimento e diâmetro nos híbridos de melão Gália 'Primal', 'Vicar', 'Total' e 'Solar King', que foram classificados como esféricos. No 'Solar King', esses autores registraram, em média, $1.048,9 \mathrm{~g}$ de massa, $3,92 \mathrm{~cm}$ de espessura de polpa e índice de rendilhamento igual a $3(50 \%$ liso e $50 \%$ rendilhado).

De acordo com Kader (1992), em melões rendilhados, a homogeneidade de rendilhamento é considerada um fator de qualidade, sendo um dos critérios avaliados durante a comercialização.

\section{Nuclear \\ Tomografia de Ressonância Magnética}

Analisando-se a forma, a localização e os tons de cinza nas imagens em tomografia de ressonância magnética, observou-se uma estrutura íntegra, com polpa uniforme e firme, com ausência de sintomas de senescência (Figura 1). As imagens sugerem que, na região do mesocarpo, mais próxima da cavidade central, os tons de cinza mais claros indicaram água mais livre (Figura 1A), sugerindo um metabolismo mais acentuado e o amadurecimento mais avançado nos tecidos do centro do fruto.

Este comportamento também foi observado por Passam e Bird (1978) durante o amadurecimento do melão Honeydew. Analisando discos de tecidos em cinco estádios de amadurecimento, os autores verificaram que a ascensão respiratória foi antecipada e maior nos tecidos próximos à cavidade interna, resultando em maior consumo de carboidratos, principalmente sacarose, como substrato respiratório. Nos tecidos próximos ao exocarpo, não se observou ascensão respiratória.
Segundo Combrink et al. (2001), a quantidade de açúcares existentes na polpa (mesocarpo) é bastante superior à quantidade existente no exocarpo e nas sementes. Este comportamento concorda com o maior consumo de carboidratos pelo processo respiratório no mesocarpo, observado por Passam e Bird (1978), e com as imagens de tomografia de ressonância magnética nuclear deste trabalho.

A tomografia de ressonância magnética nuclear também foi utilizada como método não destrutivo, para avaliar a estrutura interna de outros produtos, como pera (WANG; WANG, 1989), caqui (CLARK; MCFALL, 1996), maçã (GONZALEZ et al., 2001), goiaba (MATTIUZ et al., 2002) e figo (BISCEGLI et al., 2003).

\section{Caracterização anatômica}

Em frutos do tipo baga, o exocarpo é derivado da epiderme externa do ovário, enquanto o mesocarpo é originado do mesofilo ovariano, e o endocarpo, da epiderme interna que delimita o lóculo (SOUZA, 2006). Na formação do melão, as divisões celulares ocorrem preferencialmente na fase pré-antese, sendo que, após a antese, ocorre aumento na massa e no volume celular do fruto. Os frutos tendem a alongarse nos primeiros três dias após a antese, havendo transformações significativas na sua forma até os 11 dias; posteriormente, o formato não é alterado (COMBRINK et al., 2001).

O exocarpo no fruto maduro é caracterizado por epiderme unisseriada, com células poligonais em seção paradérmica e com arranjo em paliçada em seção transversal, e paredes periclinais externas, e parte das anticlinais mais espessadas e lignificadas (Figura 2). Essas regiões mais espessas da parede também são impregnadas por cutícula, com grande quantidade de ceras epicuticulares em forma de escamas na superfície, como também verificado por Webster e Craig (1976). Também são observados estômatos e tricomas tectores pluricelulares e unisseriados (Figura 2), ou apenas cicatrizes deixadas pela queda desses tricomas, dispersos entre as demais células epidérmicas.

A constituição de uma barreira natural pela deposição de cutícula na superfície dos frutos pode contribuir para o controle da perda de umidade e proporcionar resistência mecânica ao tecido (BARGEL; NEINHUIS, 2005). Nos vegetais, a cutícula é um composto natural que recobre a epiderme como uma membrana extracelular contínua, constituída basicamente de dois componentes: a cutina, um biopolímero insolúvel, e os lipídeos, coletivamente chamados de cera (KOLATTUKUDY, 1980). Esta é produzida pelas células epidérmicas e lançada externamente durante o desenvolvimento do fruto (KEISERMAN et al., 2004). 
No exocarpo, são abundantes as regiões de rendilhamento, características da espécie Cucumis melo var. reticulatus, a qual pertence o melão Gália. O rendilhamento é formado por fissuras na superfície, preenchidas por células de arranjo frouxo que se projetam acima da superfície (Figura 3A e B). De acordo com Webster e Craig (1976), o melão passa por um curto período de divisões celulares, seguindo-se as fases de diferenciação e aumento de tamanho do fruto, que justificariam as fissuras na epiderme e a formação de periderme a partir de camadas subepidérmicas dessas regiões. Esses autores verificaram que, após a formação da periderme, ocorre o desenvolvimento de estrutura tipicamente lenticelar, com células de preenchimento e súber projetando-se acima da superfície. Em seção transversal (Figura 3C e D), pode-se observar que as regiões de rendilhamento correspondem estruturalmente a lenticelas, onde a atividade meristemática pode ser observada pela formação de novas células pequenas, de paredes delgadas e alinhadas radialmente (Figura 3C).

Este fato pode sugerir que as lenticelas tenham função no processo de trocas gasosas no fruto durante e após a maturação (PAULL;SRIVASTAVA, 2006), principalmente considerando-se o fato de os estômatos perderem a funcionalidade com a maturação do fruto pelo acúmulo excessivo de cutícula (WEBSTER;CRAIG, 1976).

Durante o desenvolvimento de melões Gália, Combrink et al. (2001) constataram que, nos primeiros dias após a polinização, ocorreu aumento significativo no número de células do pericarpo. Aos 14 dias após a antese, houve aumento na espessura da cutícula e no tamanho celular, que causou rachadura na camada epidérmica, originando lenticelas; estas estavam completamente desenvolvidas aos 28 dias após a antese. Após este período, a periderme teve um desenvolvimento contínuo, de modo que as lenticelas se tornaram interconectadas aos 42 dias após a antese, constituindo a malha rendilhada na superfície do fruto.

Conforme Webster e Craig (1976), as lenticelas constituem uma camada biconvexa de células, com grande atividade meristemática, derivadas do felogênio. O aumento no número destas células, proporcionado pela atividade meristemática, faz sobressair certa quantidade de células na superfície do órgão, as quais se tornam suberizadas e morrem.

As características anatômicas e morfológicas dos frutos podem influenciar no aspecto fisiológico e na qualidade pós-colheita (KEISERMAN et al., 2004; PAULL; SRIVASTAVA, 2006). Em tomates, as diferenças anatômicas e morfológicas foram consideradas um dos fatores responsáveis pelas di- ferenças entre variedades, quanto ao comportamento fisiológico e bioquímico durante o amadurecimento. Frutos da variedade 'Pusa Gaurav', que possuíam menor número de lenticelas, tiveram menor perda de umidade e menor atividade respiratória, comparados aos frutos da variedade 'Pusa Ruby', durante o amadurecimento (PAULL;SRIVASTAVA, 2006).

Segundo Keiserman et al. (2004), entre variedades de melão lisos e rendilhados, o padrão de crescimento sigmoidal simples e a expansão celular não diferiram durante o desenvolvimento dos frutos. Entretanto, durante o período de máximo crescimento dos frutos, os melões rendilhados tiveram maior quantidade de cutícula do que variedades de casca lisa. Nas variedades lisas, a deposição de cutícula ocorreu sobre as células epidérmicas, no final do crescimento do fruto, enquanto nas variedades rendilhadas, a deposição de cutícula ocorreu entre as células epidérmicas, durante a fase de expansão celular. Nas variedades lisas, a elasticidade celular foi mantida e não ocorreram rachaduras. Nas variedades rendilhadas, as células epidérmicas apresentaram menor superfície de contato com as células adjacentes devido à deposição de cutícula e menor número de células por unidade de área na superfície do fruto. A elasticidade foi reduzida durante a expansão celular, e os frutos foram suscetíveis à rachadura e à formação de periderme.

As células do exocarpo são praticamente impermeáveis, como resultado da deposição de cutícula em suas paredes. O excesso de umidade na superfície do fruto, com o contato deste com o solo úmido, durante o seu desenvolvimento, pode impedir a suberização e induzir a formação de calo, em vez de rendilhamentos, originando uma mancha no tecido em contato com o solo (GALAZ, 2006), que reduz a qualidade do fruto e a resistência a injúrias.

O mesocarpo é espesso e multisseriado, com células geralmente isodiamétricas, e de paredes pectocelulósicas (Figura 4). Na região próxima ao exocarpo, as células do mesocarpo são de natureza colenquimática, menores e mais adensadas, com campos de pontoação muito evidentes. $\mathrm{O}$ restante do mesocarpo é composto por células de natureza parenquimática, mais volumosas, com espaços intercelulares proeminentes. Estas características indicam que as camadas mais externas do mesocarpo estão mais relacionadas à resistência mecânica, e as camadas mais internas, relacionadas ao acúmulo de material, provavelmente nos vacúolos.

Tecidos com células grandes e com espaços intercelulares maiores são geralmente mais frágeis do que os tecidos com células pequenas e com espaços intercelulares menores (HARKER et al., 1997). 
Segundo esses autores, as células menores, geralmente, possuem paredes celulares mais espessas, com mais citoplasma e menor quantidade de vacúolos por volume de tecido, comparadas às células maiores.

Além disto, a pressão de turgor também é muito importante. Tecidos com elevado turgor celular podem sofrer ruptura da parede celular, enquanto tecidos com baixo turgor podem promover a separação celular e a redução na firmeza durante o amadurecimento, como observado em maçã (JOHNSTON et al., 2002).

Uma das funções do parênquima é o acúmulo de diferentes materiais de reserva, que podem ser encontrados em solução no vacúolo, ou em forma de partículas sólidas ou líquidas no citoplasma (FAHN, 1989). Açúcares, carboidratos solúveis e substâncias nitrogenadas podem ser encontrados nos vacúolos (FAHN, 1989), como acontece no melão, que possui a sacarose como o principal carboidrato de reserva do fruto (GAO et al., 1999; COMBRINK et al., 2001; VILLANUEVA et al., 2004).
De acordo com Combrink et al. (2001), a redução no amido e o aumento de fósforo nas folhas do meloeiro durante as últimas semanas de desenvolvimento dos frutos coincidiram com o aumento nas concentrações de glicose, frutose e sacarose. $\mathrm{O}$ fósforo, provavelmente, atuou como um veículo na mobilização destes carboidratos através da membrana celular. Neste período, o amido das folhas foi transformado em carboidratos solúveis para ser translocado para as células adjacentes, coincidindo com a mobilização de carboidratos durante a maturação dos frutos. O conteúdo de sacarose aumentou de $50,4 \mathrm{~g}$ aos 35 dias após a antese, para $111,6 \mathrm{~g}$ por fruto aos 42 dias após a antese, indicando que o amido das folhas foi mobilizado somente nas últimas semanas de desenvolvimento dos frutos.

Os feixes vasculares foram encontrados dispersos no mesocarpo, e caracterizados com bicolaterais (Figura 5), característicos da família Cucurbitaceae (BARBER, 1909). Os feixes vasculares são responsáveis pelo transporte de seiva solúvel dos locais de produção, como as folhas, até a região de acúmulo, como os frutos.

TABELA 1 - Características do melão Gália ‘Solar King', no ponto de colheita

\begin{tabular}{lc}
\hline \multicolumn{1}{c}{ Características } & Média \\
\hline Massa $(\mathrm{g})$ & $1021,97 \pm 5,36$ \\
Espessura de polpa $(\mathrm{cm})$ & $3,91 \pm 0,06$ \\
Comprimento $(\mathrm{cm})$ & $12,91 \pm 0,36$ \\
Diâmetro $(\mathrm{cm})$ & $11,96 \pm 0,12$ \\
Relação de formato & 1,08 \\
Índice de rendilhamento & 4,0 \\
\hline
\end{tabular}



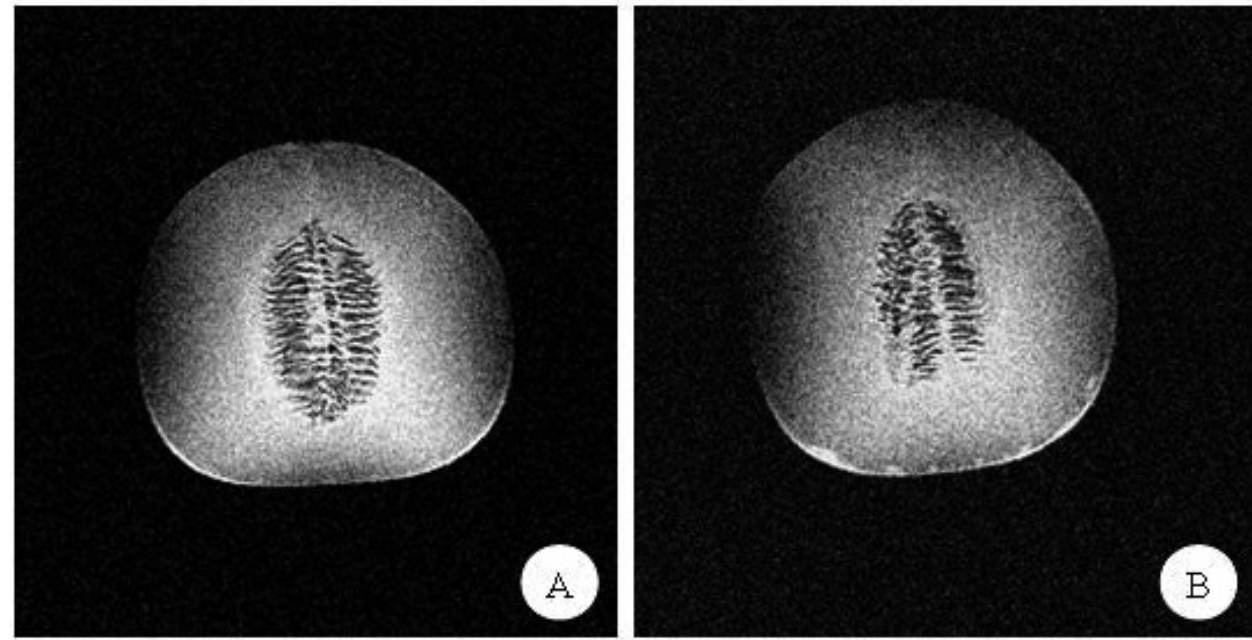

FIGURA 1 - Tomogramas de ressonância magnética nuclear do melão Gália 'Solar King', 48 h após a colheita. (A) corte passando pelo centro do fruto, e (B) corte espaçado de $1 \mathrm{~cm}$ do centro do fruto.

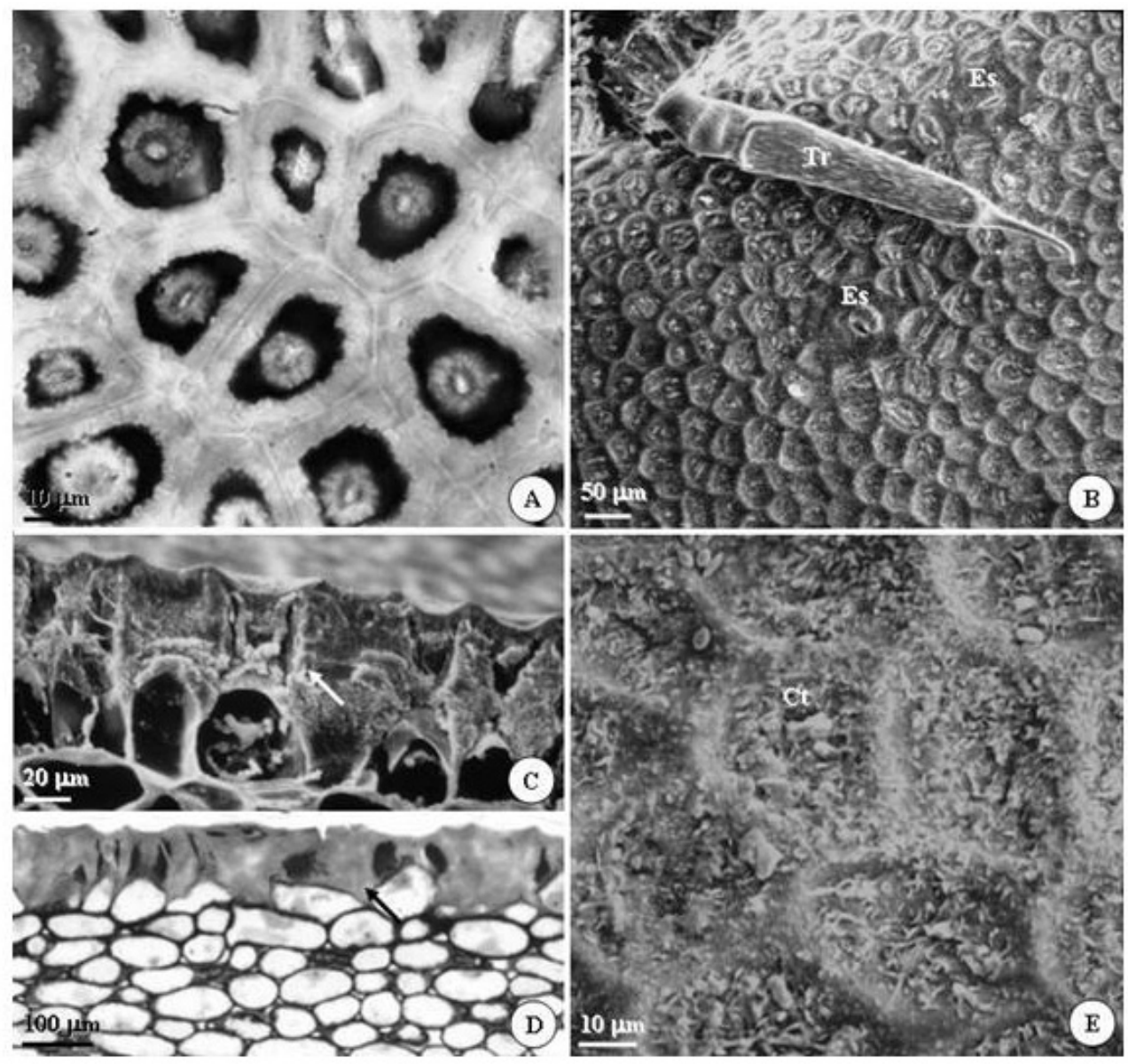

FIGURA 2 - Fotomicrografias (A e D) e eletromicrografias de varredura (B, C e E) do melão Gália 'Solar King'. (A) Seção paradérmica. Células do exocarpo com paredes espessas e lignificadas. (B) Superfície do exocarpo. (C e D) Seções transversais do pericarpo. As setas indicam as paredes espessas das células epidérmicas. (E) Superfície do exocarpo, com ceras epicuticulares em forma de escamas. Tr: tricoma. Es: estômato. Ct: cutícula. 

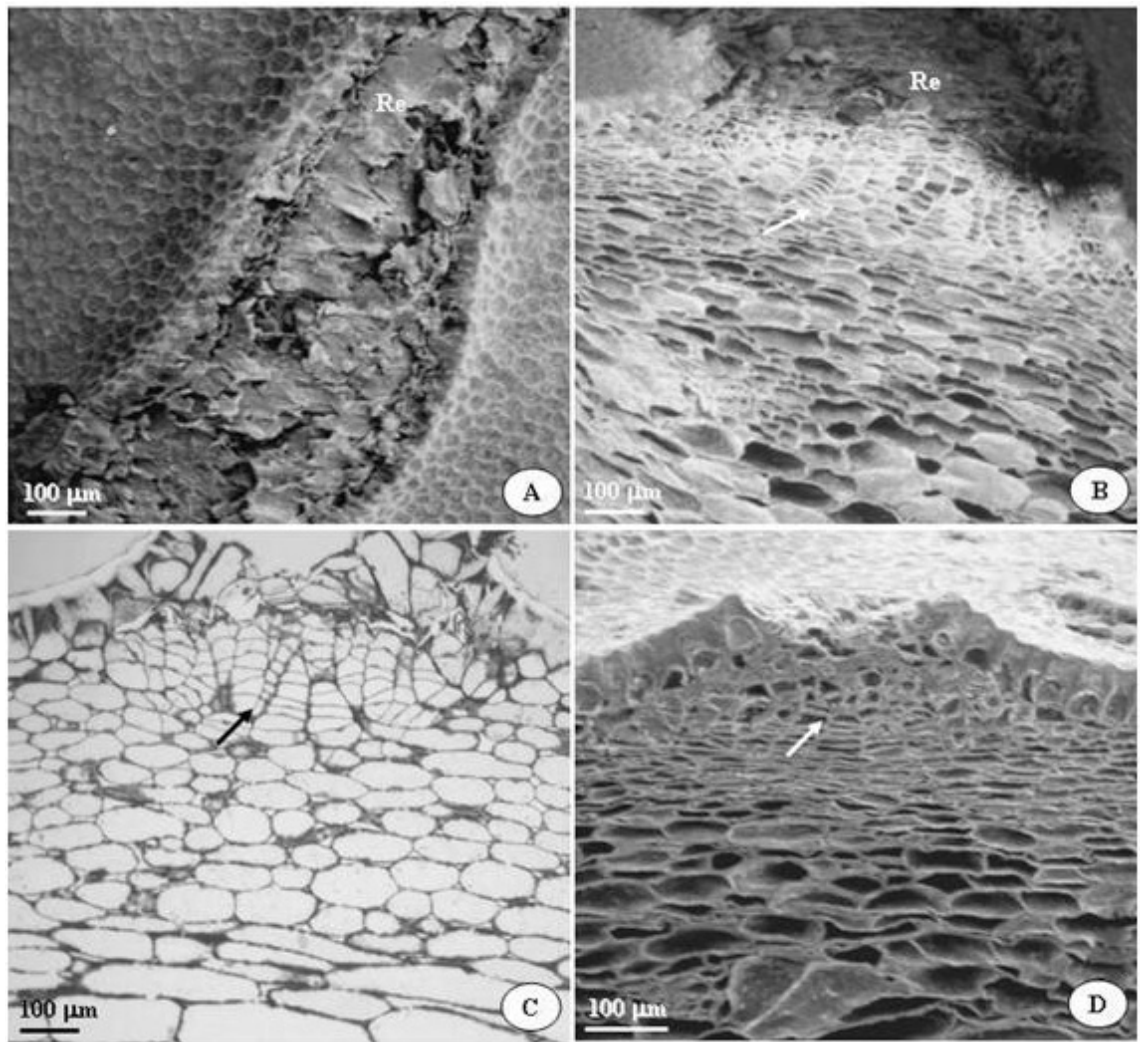

FIGURA 3 - Eletromicrografias de varredura (A, B e D) e fotomicrografia (C) no melão Gália 'Solar King'.

(A) Superfície do exocarpo. (B-D) Região de rendilhamento em seção transversal, evidenciando a estrutura lenticelar. Re: rendilhamento (setas).

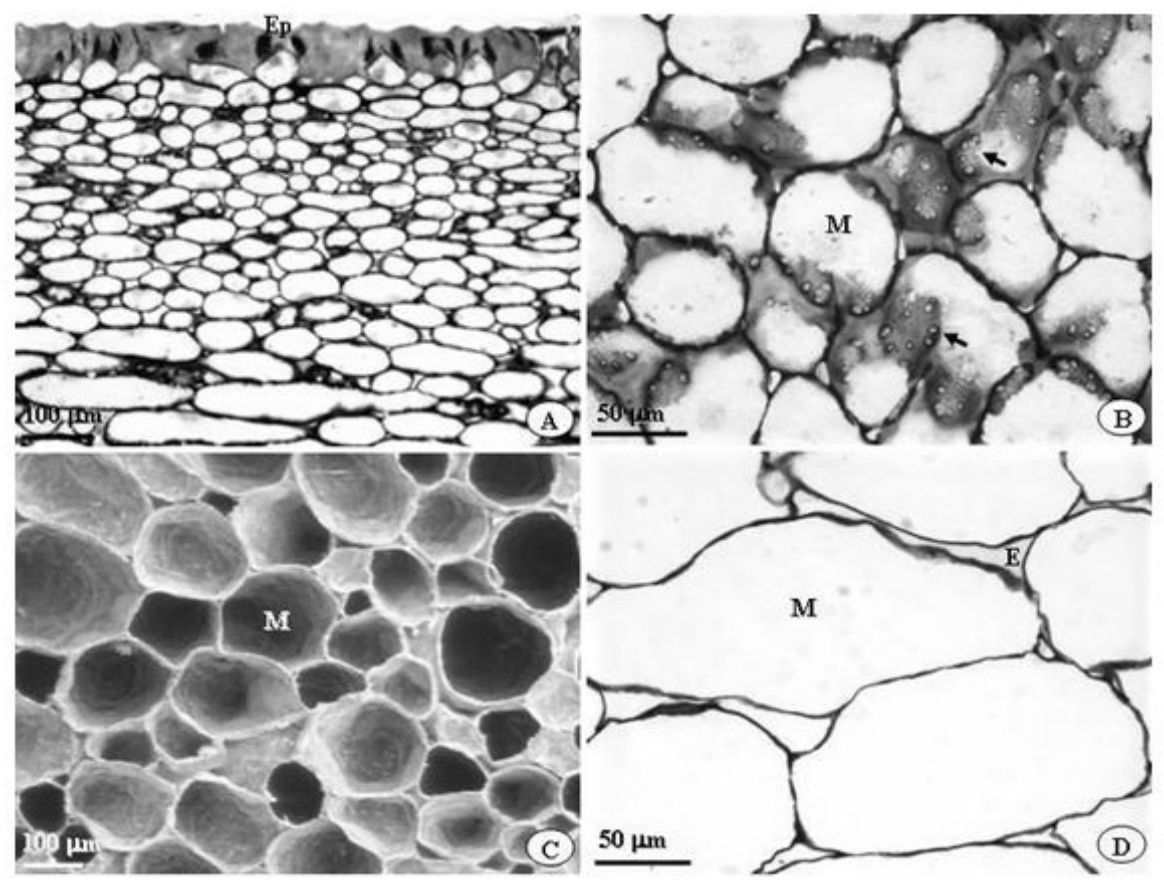

FIGURA 4 - Fotomicrografias (A, B e D) e eletromicrografia de varredura (C) do melão Gália 'Solar King'. (A) Pericarpo em seção transversal. (B e C) Mesocarpo em seção paradérmica, onde os campos de pontoação (setas) são evidentes. (D) Mesocarpo em seção transversal. Ep: epiderme. M: mesocarpo. E: espaços intercelulares. 


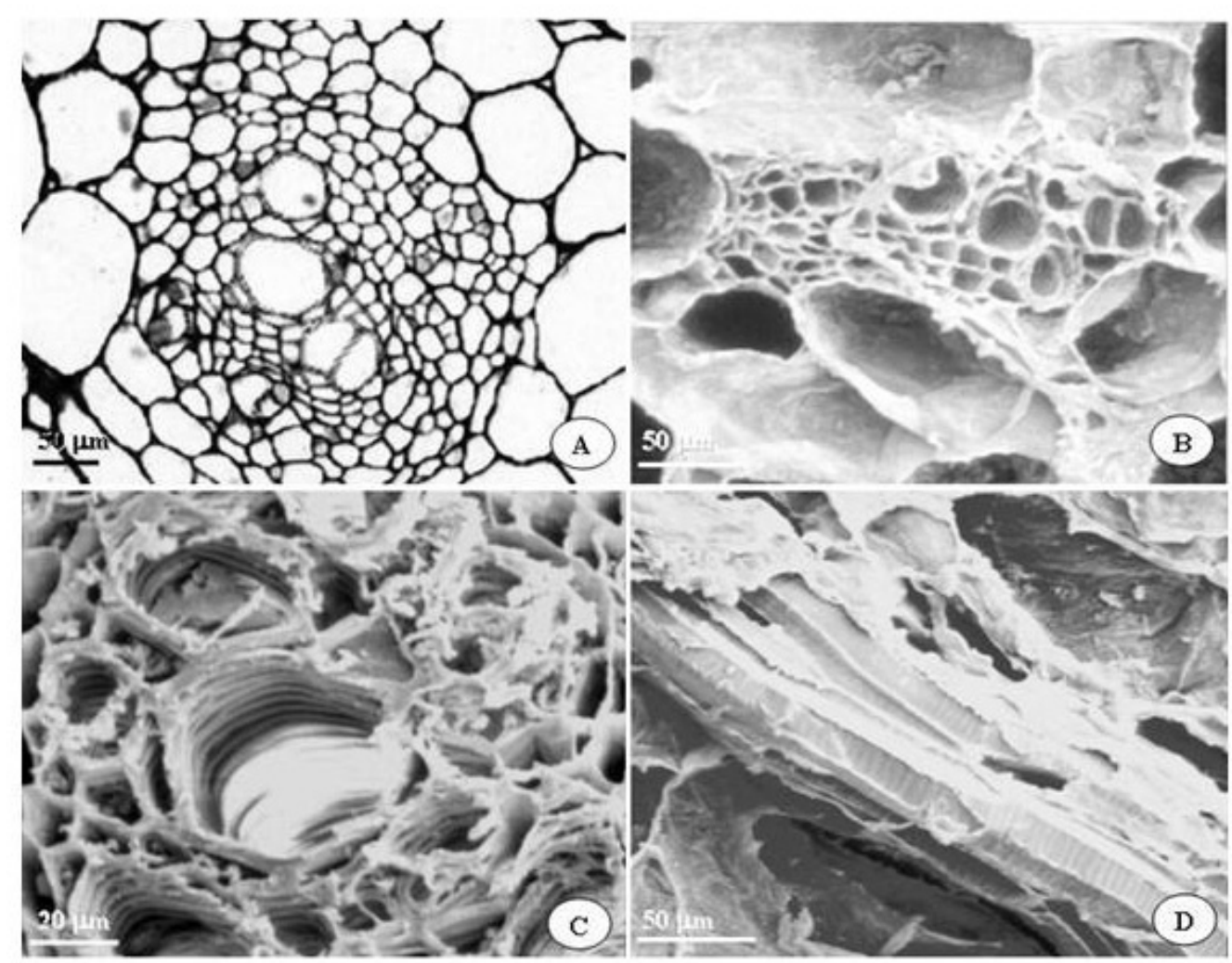

FIGURA 5 - Fotomicrografia (A) e eletromicrografias de varredura (B, C e D) de regiões com feixes vasculares, no mesocarpo do melão Gália 'Solar King'. (A, B e C) Seções transversais. (D) Seção longitudinal.

\section{CONCLUSÕES}

1-A análise das imagens sugere que, na região do mesocarpo, próxima da cavidade central, há metabolismo acentuado e amadurecimento mais avançado dos tecidos que podem ser responsáveis pelo deslocamento da placenta e o amaciamento mais rápido dos tecidos em volta da cavidade interna.

2-No ponto de colheita, observam-se áreas rendilhadas, cera epicuticular e estrutura adensada das primeiras camadas parenquimáticas que podem contribuir para o controle da perda de umidade do fruto e a resistência às injúrias mecânicas.

\section{REFERÊNCIAS}

BARBER, K. G. Comparative histology of fruits and seeds of certain species of cucurbitaceae. Botanical Gazzete, Chicago, v. 47, p. 263-310, 1909.
BARGEL, H.; NEINHUIS, C. Tomato (Lycopersicon esculentum Mill.) fruit growth and ripening as related to the biomechanical properties of fruit skin and isolated cuticle. Journal of Experimental Botany, Oxford, v. 56, n. 413, p. 1049-1060, 2005.

BISCEGLI, C. I.; FERRAZ, A. C. de O.; HONÓRIO, S. L.; SIMÕES, M. L.; SILVA, W. T. L. da. Uso da tomografia de ressonância magnética para diagnosticar os efeitos de injúrias mecânicas em figos 'Roxo de Valinhos'. São Carlos: EMBRAPACNPDIA. 2003. p. 1-4 (Comunicado Técnico, 52).

BISOGNIN, D. A. Origem e evolução de cucurbitáceas cultivadas. Ciência Rural, Santa Maria, v.32, n.5, p. 715-723, 2002.

CLARK, C. J.; MacFALL, J. S. Magnetic ressonance imaging of persimmon fruit (Diospyros kaki) during storage at low temperature and under modified atmosphere. Postharvest Biology and Technology, Amsterdam v. 9, p. 97-108, 1996. 
COMBRINK, N. J. J.; AGENBAG, G.A.; LANGENHOVEN. Anatomical and compositional changes during fruit development of 'Galia' melons. South African Journal of Plant Soil, Pretoria, v.18, n. 1, p. 7-14, 2001.

FAHN A. Plant Anatomy. $3^{\text {rd }}$ ed. Oxford: Pergamon Press, 1989.544p.

FREITAS, J. de A. D. de (Ed.). Normas técnicas e documentos de acompanhamento da produção integrada de melão. Fortaleza: Embrapa Agroindústria Tropical, 2003. 89 p. (Documentos, 68).

GALAZ, L. G. Desarrollo del reticulado y daño por frío en frutos de cultivares de melón (Cucumis melo L. Grupo Cantalupensis). Santiago: Pontificia Universidad Católica de Chile, 2006. 32 p. Proyecto de Título

GAO, Z.; PETREIKOV, M.; ZAMSKI, E.; SCHAFFER, A. A. Carbohydrate metabolism during early fruit development of sweet melon (Cucumis melo). Physiologia Plantarum, Copenhagen, v.106, p.1-8, 1999.

GONZALEZ, J. J.; VALLE, R. C.; BOBROFF, S.; BIASI, W.V.; MITCHAM, E. J.; McCARTHY, M. J. Detection and monitoring of internal browning development in 'Fuji' apples using MRI. Postharvest Biology and Technology, Amsterdam, v. 22, p. 179-188, 2001.

HARKER, F. R.; STEC, M. G. H.; HALLETT, I. C.; BENNETT, C. L. Texture of parenchymatous plant tissue: a comparison between tensile and other instrumental and sensory measurements of tissue strength and juiciness. Postharvest Biology and Technology, Amsterdam, v. 11, p. 63-72, 1997.

JOHNSTON, J. W.; HEWETT, E. W.; HERTOG, M. L. A. T. M. Postharvest softening of apple (Malus domestica) fruit: a review. New Zealand of Crop and Horticultural Science, Wellington, v. 30, p. 145-160, 2002.

KADER, A. A. Postharvest technology of horticultural crops. California: University of California, $1992.519 \mathrm{p}$.

KARNOVSKY, D.A.A. Formaldehyde-glutaraldehyde fixative of high osmolarity for use in electron microscopy. Journal of Cell Biology, New York, v. 27, p.137-138, 1965.
KAYS, S. J. Postharvest physiology of perishable plant product. New York: Van Nostrand Reinhold, $1991.532 \mathrm{p}$.

KEISERMAN, K.; TANAMI, Z.; SHOSEYOV, O.; GINZBERG, I. Differing rind characteristics of developing fruits of smooth and netted melons $(\mathrm{Cu}$ cumis melo). Journal of Horticultural Science \& Biotechnology, Kent, v. 79, n. 1, p. 107-113, 2004

KITAJIMA, E. W. Curso introdutório de microscopia eletrônica de varredura. São Paulo: ESALQ, 1997. $37 \mathrm{p}$.

KOLATTUKUDY, P. E. Biopolyester membranes of plants: cutin and suberin. Science, London, v.208, p. $990-1000,1980$.

KRAUS, J. E.; ARDUIN, M. Manual básico de métodos em morfologia vegetal. Rio de Janeiro: Ed. Universidade Rural, 1997. 198p.

LORENZI, H.; BACHER, L.; LACERDA, M.; SARTORI, S. Frutas brasileiras e exóticas cultivadas. São Paulo: Instituto Plantarum de Estudos da Flora, 2006. $640 \mathrm{p}$.

MATTIUZ, B. H.; BISCEGLI, C. I.; DURIGAN, J. F. Aplicações de tomografia de ressonância magnética nuclear como método não destrutivo para avaliar os efeitos de injúrias mecânicas em goiabas 'Paluma' e 'Pedro Sato'. Revista Brasileira de Fruticultura, Jaboticabal, v.24, n.3, p. 641-643, 2002.

MENEZES, J.B. Qualidade pós-colheita de melão tipo Gália durante a maturação e o armazenamento. 1996. 157 p. Tese (Doutorado em Tecnologia de Alimentos) - Universidade Federal de Lavras, Lavras , 1996.

MORAIS, P. L. D.de; MENEZES, J. B.; OLIVEIRA, O. F. de. Potencial de vida útil pós-colheita de quatro genótipos de melão tipo Gália. Ciência Agrotécnica, Lavras, v. 28, n.6, p. 1314- 1320, 2004.

PASSAM, H. C.; BIRD, M. C. The respiratory activity of Honeydew melons during the climacteric. Journal of Experimental Botany, London, v. 29, n. 109, p. 325-333, 1978.

PAUL, V.; SRIVASTAVA. Role of surface morphology in determining the ripening behaviour of tomato (Lycopersicon esculentum Mill.) fruits. Scientia Horticulturae, Amsterdam, v. 110, p. 84-92, 2006. 
SOUZA, L. A. de (Ed.). Anatomia do fruto e da semente. Ponta Grossa: Editora UEPG, 2006. 200p.

TORRES, J. M. Los tipos de melón comerciales. In: VALLESPIR, A. N. (Coord.). Melones. Reus: Horticultura, 1997. cap.1, p.12-19 (Compendios de Horticultura, 10).

VILLANUEVA, M. J.; TENORIO, M. D.; ESTEBAN, M. A.; MENDOZA, M.C. Compositional changes during ripening of two cultivars of muskmelon fruits. Food Chemistry, Chicago, v. 87, p. $179-185,2004$.
WANG, C. Y.; WANG, P. C. Nondestructive detection of core breakdown in 'Bartlett' pears with nuclear magnetic resonance imaging. HortScience, Alexandria, v. 24, n.1, p. 106-109, 1989.

WEBSTER, B. D.; CRAIG, M. E. Net morphogenesis and characteristics of the surface of muskmelon fruit. Journal of the American Society for Horticultural Science, Alexandria, v.101, n. 4, p. 412-415, 1976. 